\title{
Synthesis, Structural and Mechanical Properties of Electroplated Nifemo Nanocrystalline Thin Films
}

\author{
R.Kannan, M.Selvambikai, E.Selva kumar, S. Venkateshwaran
}

\begin{abstract}
This study focuses on nano crystalline thin film coating of NiFeMo on the surface of mild steel at three different bath temperatures such as $60^{\circ} \mathrm{C}, \quad 70^{\circ} \mathrm{C}$ and $80^{\circ} \mathrm{C}$ by elctrodeposition technique. Surface analysis and elemental compositional analysis of coated thin films have been employed with the help of SEM images, EDAX and XRD patterns. Electrochemical technique has been used to investigate corrosion behaviour on electroplated NiFeMo thin films. SEM analysis confirms that the existence of bright and spherical shaped granules and crack free surface on the coated film. The particle size of coated thin film was calculated using Scherrer formula and it was in the range of few nanometres. XRD study confirms that the film coated at elevated bath temperature has tetragonal structure and the remaining have mixed phase of cubic and $\mathrm{HCP}$ structures. Electrochemical studies discloses that all the NiFeMo thin films coated at three different temperatures have better corrosion resistance as compared with NiFe and NiFeW thin films. Among the three different bath temperatures the film coated at $60^{\circ} \mathrm{C}$ has better corrosion resistance as $150.17 \Omega$. Based on the obtained structural and corrosion results of the synthesised thin films, they are highly suitable for manufacturing of MEMs and NEMs devices
\end{abstract}

Keywords: Corrosion resistance, electrodeposition, molybdenum, MEMS and NEMS

\section{INTRODUCTION}

Now a day's very powerful sensors and actuators are promisingly produced by means of MEMs and NEMs technology. Miniaturization, optimization and cost reduction are the major advancements in MEMs and NEMs based electronic devices but they have been limited by the electrical, magnetic and mechanical properties of thin magnetic alloy coatings. There are wide variety of magnetic alloys that can be plated for MEMs and NEMs, among those $\mathrm{NiFe}$ is the popular alloy because of its low internal stress, low magnetostriction, good mechanical properties, high saturation magnetization and high permeability [1-4]. But controlling corrosion behavior and enhancing magnetic properties of $\mathrm{NiFe}$ are still a challenge. In the recent days researchers looking for suitable third metal element to enrich the corrosion resistance and magnetic properties of $\mathrm{NiFe}$ [5-8]. Generally refractory metal elements such as tungsten, molybdenum, niobium, tantalum etc., have very good mechanical properties such as high tensile strength, highest young's modulus of elasticity, and high corrosion resistance, excellent thermal properties like high melting point and low coefficient of linear thermal expansion. In this study, the refractory metal element Molybdenum (Mo) which attributesmelting point of $2620^{\circ} \mathrm{C}$, thermal expansion of $4.8 \mu \mathrm{m} / \mathrm{m} . \mathrm{K}$, young's modulus of $329 \mathrm{GPa}$, Vickers hardness of 1400-2740 GPa, was chosen as a third element and NiFeMo was coated on the surface of mild steelplate. Amid various coating techniques electroplating method was employed because the properties of coated thin film on the substrate can easily be controlled by varying electrolyte concentration and deposition parameters [9-12]. In this research work NiFeMo alloy was successfully electroplated on the surface of mild steel substrate at different bath temperatures such as $60^{\circ} \mathrm{C}, 70^{\circ} \mathrm{C}$ and $80^{\circ} \mathrm{C}$.

\section{EXPERIMENT}

The NiFeMo alloy was coated as thin film on mild steel substrate by electro deposition method at three different bath temperaturessuch as $60^{\circ} \mathrm{C}, 70^{\circ} \mathrm{C}$ and $80^{\circ} \mathrm{C}$. Electrolyte bath was prepared by dissolving all the required reagent graded chemicals in triple distilled water. Few drops of ammonia solution was addedin the bath with the intension to adjust the $\mathrm{PH}$ value to 8 . Table 1 shows the chemical composition and optimized bath conditions. Mild steel plate of $7.5 \mathrm{~cm}$ length and $1.5 \mathrm{~cm}$ breadth was used as cathode and the same dimension of pure stainless steel plate was used as an anode. Initially both the plates were well cleaned with soap water and further dipped in sulphuric acid for fine cleaning and finally rinsed with triple distilled water. Adhesion tap was used to mask off the surface area which are not desired for the thin film coating. The NiFeMo alloy was electrodeposited at three different temperatures such as $60^{\circ} \mathrm{C}, 70^{\circ} \mathrm{C}$ and $80^{\circ} \mathrm{C}$ by applying constant current density of $1 \mathrm{~A} / \mathrm{dm}^{2}$. Several characterization techniques like SEM , EDAX ,XRD and electrochemical studies have been employed for all the coated thin films and the results are presented here.

Revised Manuscript Received on Septmber 10, 2019

R.Kannan, Department of Science and Humanities - Physics Division Kumaraguru College of Technology, Coimbatore, Tamilnadu, India

M.Selvambikai, Department of Science and Humanities - Physics Division, Kumaraguru College of Technology, Coimbatore, Tamilnadu, India

(Email: selvambikai.m.sci@kct.ac.in)

E.Selva kumar, Department of Mechanical Engineering, Kumaraguru College of Technology, Coimbatore, Tamilnadu, India

S. Venkateshwaran, Department of Mechanical Engineering, Kumaraguru College of Technology, Coimbatore, Tamilnadu, India 
Table1. Optimizationof bath conditions forNiFeMo.

\begin{tabular}{|l|l|l|}
\hline S.No & $\begin{array}{l}\text { Name of the chemical } \\
\text { parameters }\end{array}$ & Data \\
\hline 1 & Nickel sulphate & $60 \mathrm{~g} / 1$ \\
\hline 2 & Ferrous sulphate & $30 \mathrm{~g} / 1$ \\
\hline 3 & Sodium molybadate & $10 \mathrm{~g} / 1$ \\
\hline 4 & Diammonium citrate & $60 \mathrm{~g} / 1$ \\
\hline 5 & Citric acid & $5.5 \mathrm{~g} / 1$ \\
\hline 6 & Boric acid & $10 \mathrm{~g} / 1$ \\
\hline 7 & pH value & 8 \\
\hline 8 & Temperature & $\begin{array}{l}60, \quad 70 \text { and } \\
80\left({ }^{\circ} \mathrm{C}\right)\end{array}$ \\
\hline 9 & Current density & $1 \mathrm{~A} / \mathrm{dm} 2$ \\
\hline
\end{tabular}

\section{RESULT AND DISCUSSION}

\section{EDAX analysis}

EDAX analysis confirms that the deposition of nickel, iron and molybdenum particles on the surface of the mild steel plate. The EDAX spectrum indicates that the $45 \%$ of $\mathrm{Ni}, 25 \%$ of Mo and $15 \%$ of Feare coated on the mild steel surface. Figure 1 shows the EDAX spectrum of synthesized thin films.

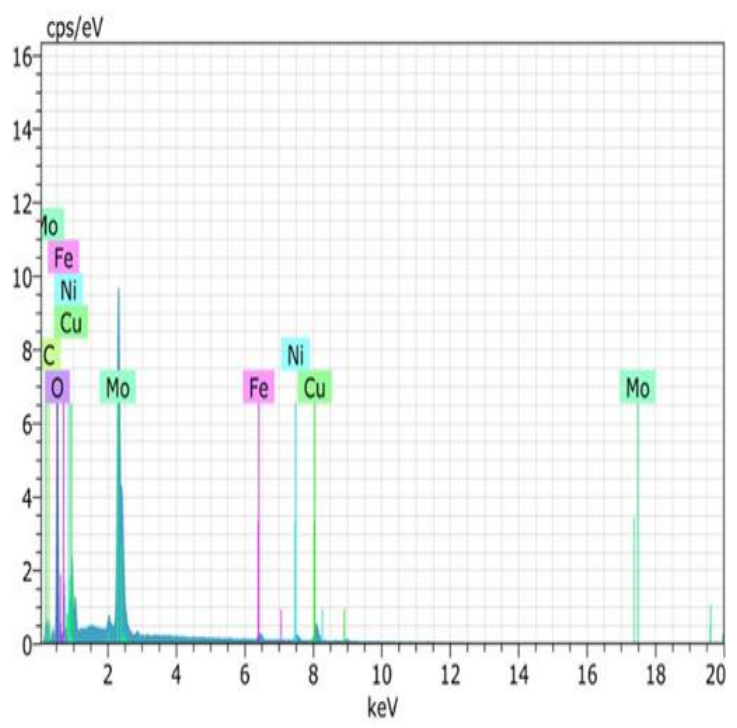

Figure 1 EDAX spectrum of NiFeMo

\section{SEM image analysis}

The micro structure and surface analysis of coated thin film samples have been analyzed from SEM images. SEM image of the NiFeMo coated area of the mild steel substrate reveals that the existence of bright and spherical shaped granules. SEM micrograph confirms that the surfaces of the coated thin films are crack free and the shape of the nano crystalline molecules changes from spherical to needle shape as the temperature increases to higher range. Figure2 shows the micro structures of the NiFeMo thin film coating.

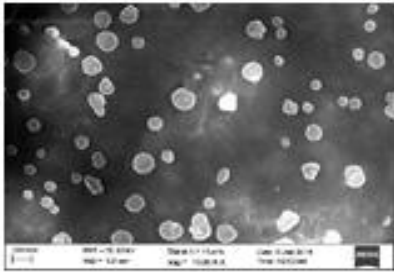

(a)

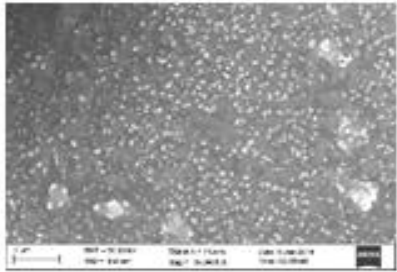

(b)

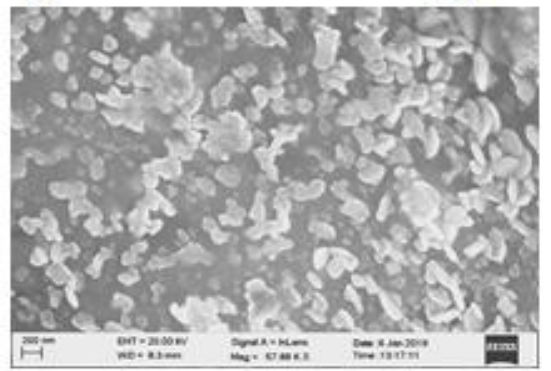

(c)

Figure 2. SEM images of NiFeMo thin films (a) coated at $60^{\circ} \mathrm{C}(\mathrm{b})$ coated at $70^{\circ} \mathrm{C}$ (c) coated at $80^{\circ} \mathrm{C}$

The NiFeMo thin film coated at bath temperature $80^{\circ} \mathrm{C}$ exhibit the needle shape and mushroom shaped particles as shown figure 2.SEM micrographs reveal that the particle diameter is decreased from $185.4 \mathrm{~nm}$ to $118.4 \mathrm{~nm}$ by increasing the bath temperature from $60^{\circ} \mathrm{C}$ to $80^{\circ} \mathrm{C}$ and pictures are shown in figure 3.

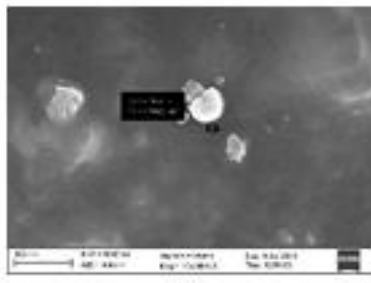

(a)

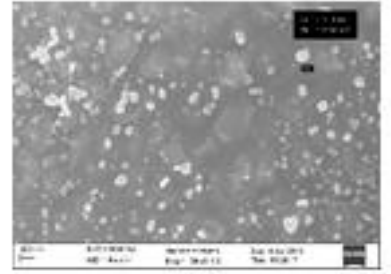

(b)

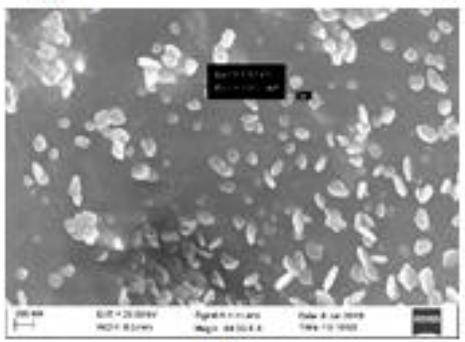

(c)

Figure 3. Particle size of NiFeMo thin films (a) coated at $60^{\circ} \mathrm{C}(\mathrm{b})$ coated at $70^{\circ} \mathrm{C}(\mathrm{c})$ coated at $80^{\circ} \mathrm{C}$

\section{$X$ Ray diffraction study}

All the synthesized NiFeMo thin films were subjected to structural analysis and the obtained graphs are shown in figure 4. $\mathrm{X}$ ray diffraction study has been used to calculate the particle size and crystalline nature of the nano crystals existing in the coated NiFeMo thin film. Particle size has been calculated from Scherrer's formula and it was found that the particle size is changing with respect to bath temperature, ranging between $25-30 \mathrm{~nm}$. The film coated at $80^{\circ} \mathrm{C}$ has the particle size of $25 \mathrm{~nm}$. This is due to the reorientation of atoms during the time of electroplating. The

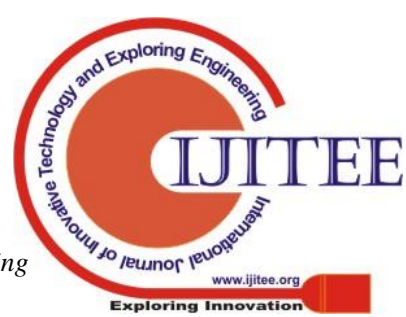


coated thin film exposes perfect cubic structure at higher bath temperature of $80^{\circ} \mathrm{C}$ and it has mixed phase of cubic and tetragonalstructures at $60^{\circ} \mathrm{C}$ and $70{ }^{\circ} \mathrm{C}$. Fig 3 shows the Xray diffraction pattern of NiFeMo thin films. The results obtained from XRD are presented in table 2.

Table 2.XRD results of NiFeMo thin films

\begin{tabular}{|l|l|l|l|l|l|}
\hline $\begin{array}{l}\text { Bath } \\
\text { temperatur } \\
\text { e }\end{array}$ & $\begin{array}{l}\mathbf{2} \boldsymbol{\theta} \\
(\mathbf{d e g})\end{array}$ & $\begin{array}{l}\text { Lattice } \\
\text { paramete } \\
\mathbf{r} \quad \mathbf{C r y s t a l l i n} \\
\left(\mathbf{A}^{\mathbf{0}}\right)\end{array}$ & $\begin{array}{l}\text { Strai } \\
\mathbf{e} \text { size D } \\
\mathbf{N m}\end{array}$ & $\begin{array}{l}\text { Dislocatio } \\
\mathbf{n} \\
\mathbf{1 0} \text { density } \\
\left.\mathbf{( 1 0}^{\mathbf{1 4}} / \mathbf{~ m}^{\mathbf{2}}\right)\end{array}$ \\
\hline 60 & 28.20 & 9.4219 & 26.67 & 13.58 & 14.0590 \\
\hline 70 & 40 & 9.4219 & 31.40 & 11.53 & 10.1424 \\
\hline 80 & 80.10 & 9.4414 & 25.25 & 14.34 & 15.6847 \\
\hline
\end{tabular}

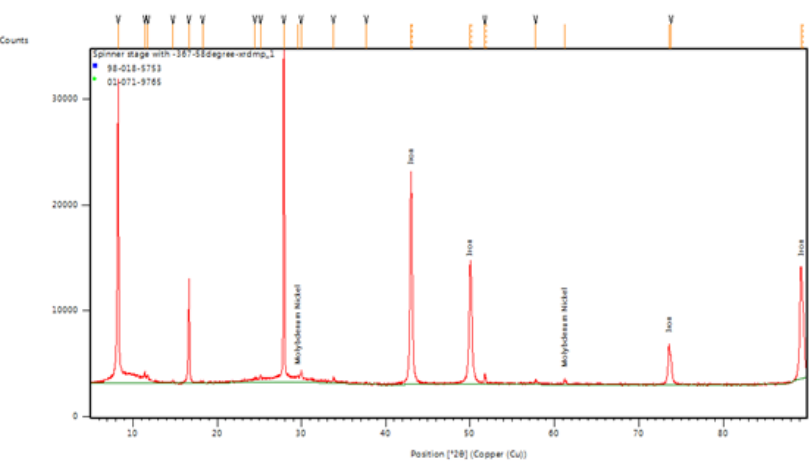

(a)

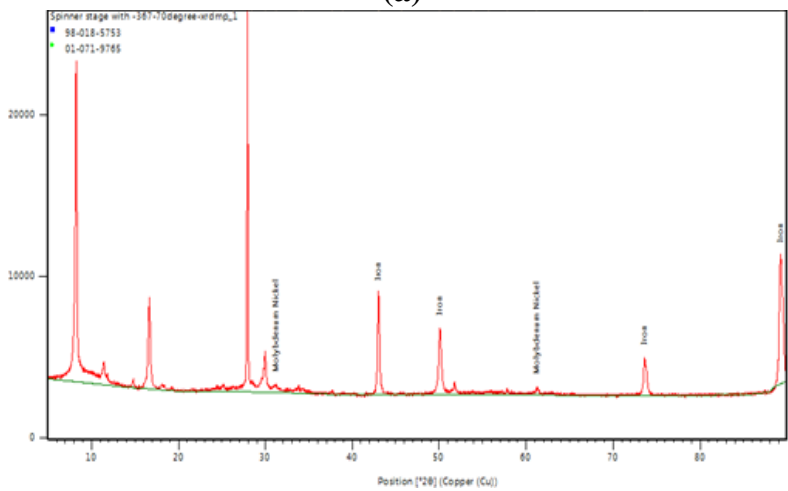

(b)

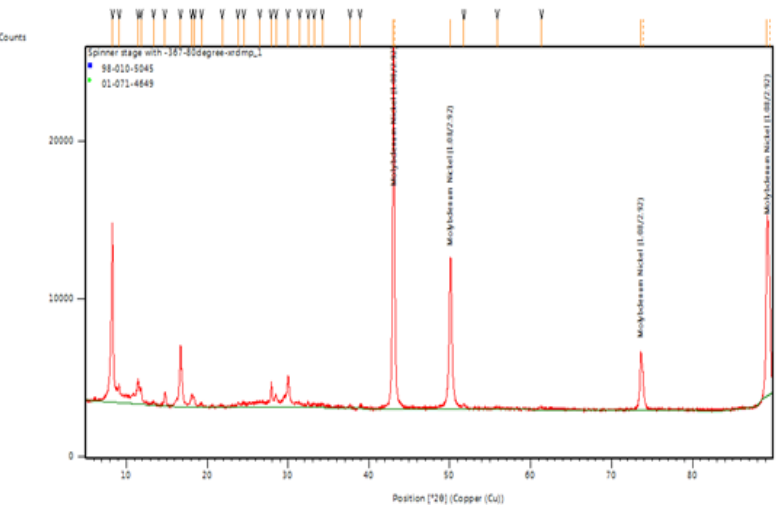

(c)

Figure 4. XRD patterns of NiFeMo thin films (a) coated at $60^{\circ} \mathrm{C}(\mathrm{b})$ coated at $70^{\circ} \mathrm{C}(\mathrm{c})$ coated at $80^{\circ} \mathrm{C}$
From XRD data, it is concluded that the NiFeMo thin films coated at higher bath temperature have approached to perfect nano level and the phase transition also occurs from mixed phase of cubic and tetragonal to perfect cubic structure.

\section{Corrosion Studies}

Corrosion behavior of NiFeMo coated thin films was analyzed using electrochemical studies such as electrochemical impedance spectroscopy and potentiodynamic polarization. The polarization parameters such as corrosion potential (Ecorr), corrosion current densities(icorr) and polarization resistance were tabulated in Table 3 and the corresponding Tafel plot is shown in fig 5 . The tabulated results which are obtained from electrochemical studies disclose that the corrosion current drastically decreases, corrosion rate tremendously falls and the corrosion resistance extremely higher at the lower temperature compared with the elevated temperatures.

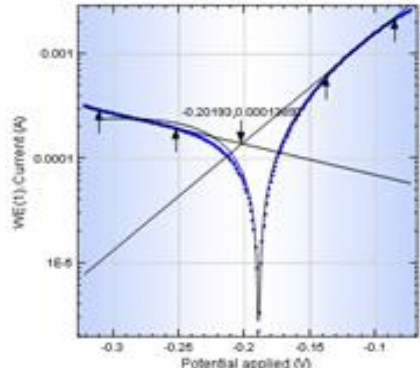

(a)

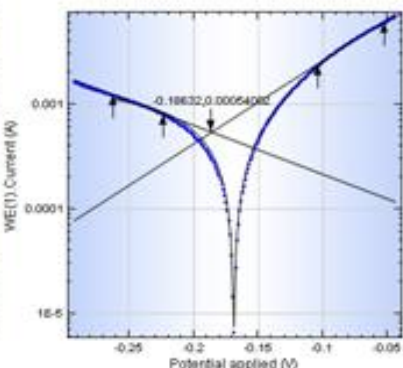

(b)

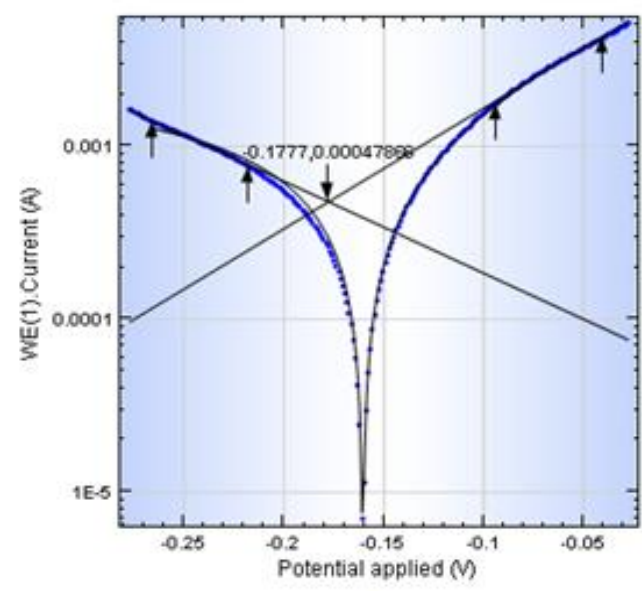

(c)

Figure 5. Polarization study of NiFeMo thin films (a) coated at $60^{\circ} \mathrm{C}(\mathrm{b})$ coated at $70^{\circ} \mathrm{C}(\mathrm{c})$ coated at $80^{\circ} \mathrm{C}$

Impedance analysis result reveals that the charge transfer resistance of the NiFeMo thin film electroplated at $60{ }^{\circ} \mathrm{C}$ is higher than the films coated at $70{ }^{\circ} \mathrm{C}$ and $80^{\circ} \mathrm{C}$. The extent of corrosion resistance is improved to $40.68 \%$ for the film coated at higher temperature. 
Table 2. Corrosion results of NiFeMo thin films

\begin{tabular}{|c|c|c|c|c|c|}
\hline $\begin{array}{l}\text { Test } \\
\text { Samples }\end{array}$ & $\begin{array}{l}\text { Ecorr, } \\
(\mathbf{V})\end{array}$ & $\begin{array}{l}\text { ba } \\
(\mathrm{V} / \mathrm{dec})\end{array}$ & $\begin{array}{l}\text { bc } \\
(\mathrm{V} / \mathrm{dec}) \\
(\mathrm{V} / \mathrm{dec})\end{array}$ & $\begin{array}{l}\text { icorr } \\
(\mathrm{A})\end{array}$ & $\begin{array}{l}\text { Polarization } \\
\text { resistance } \\
(\Omega)\end{array}$ \\
\hline $\begin{array}{l}\text { NiFeMocoat } \\
\text { ed at } 60^{\circ} \mathbf{C}\end{array}$ & $\begin{array}{l}0.2019 \\
3\end{array}$ & -0.44896 & 0.1424 & $\begin{array}{l}0.0006 \\
03\end{array}$ & 150.17 \\
\hline $\begin{array}{l}\text { NiFeMocoat } \\
\text { ed at } 70^{\circ} \mathbf{C}\end{array}$ & $\begin{array}{l}- \\
0.1863 \\
2\end{array}$ & -0.93345 & 0.20018 & $\begin{array}{l}0.0024 \\
53\end{array}$ & 45.122 \\
\hline $\begin{array}{l}\text { NiFeMocoat } \\
\text { ed at } 80^{\circ} \mathbf{C}\end{array}$ & -0.1777 & 1.6901 & 0.21321 & \begin{tabular}{|l}
0.0015 \\
26 \\
\end{tabular} & 53.871 \\
\hline
\end{tabular}

\section{CONCLUSION}

The NiFeMo alloy is successfully coated on the miled steel substrate using electrodeposition technique at three different temperatures. The surfaces of all the coated thin films are crack free. The particle size of thin films are varying with respect to the bath temperature and the particle size is reduced to $25 \mathrm{~nm}$ for the film coated at $80^{\circ} \mathrm{C}$. The corrosion resistance of the film coated at $60{ }^{\circ} \mathrm{C}$ is tremendously increased as compared with films coated at elevated temperatures.

\section{ACKNOWLEDGEMENT}

The authors would like to express their hearty thanks to the Management of Kumaraguru College of Technology, Coimbatore - 49, Tamilnadu, India for providing financial support to carry out this research work.

\section{REFERENCES}

1. Nagaraj, B., and P. Vijayakumar. "Soft computing based PID controller tuning and application to the pulp and paper industry." Sensors \& Transducers 133, no. 10 (2011): 30.

2. R Kannan et al 2018 Mater. Res. Express 5046414.

3. uanguo Zhou, Jonathan Velleuer, Peter J. Heard, and Walther Schwarzacher, Surface Roughness and Magnetic Properties of Electrodeposited NiFeMo Thin Films.Electrochem. Solid-State Lett. 2009 12(3): D7D10;.

4. A.K. Majumdar, S. Rai, Pragya Tiwari, G.S. Lodha, A. Banerjee, K.G.M Nair, Jayanta Sarkar, R.J. Choudhary, and D.M. Phase , Room temperature ferromagnetism down to 10 nanometer $\mathrm{Ni}-\mathrm{Fe}-\mathrm{Mo}$ alloy films, Mitali Banerjee,Thin Solid Films (2013) 545: 385.

5. P. B. Narayan, R. D. Silkensen, and S. Dey."Effect of annealing on the magnetics of NiFeMo thin films, Journal of Applied Physics 73, 6620 (1993); https://doi.org/10.1063/1.352530

6. Quanguo Zhou1, a), Peter J. Heard2, and Walther Schwarzacher, Fabrication and magnetic properties of patterned NiFeMo films electrodeposited in selfassembled nanosphere templates,Journal of Applied $\begin{array}{llll}\text { Physics } & 109, & 054313 & \text { (2011); }\end{array}$ https://doi.org/10.1063/1.3561362

7. R. P. Cowburn, D. K. Koltsov, A. O. Adeyeye, M. E. Welland, and D. M. Tricker, Phys. Rev. Lett. 83, 1042 (1999).

8. Kannan R, Ganesan S, Selvakumari TM (2012) Synthesis and characterization of nanocrystallineNiFeWS thin films in diammonium citrate bath. Digest J Nanomater Biostruct 7(3):1039-1050.
9. Agalya, A., B. Nagaraj, and K. Rajasekaran "Concentration control of continuous stirred tank reactor using particle swarm optimization algorithm." Trans Eng Sci 1, no. 4 (2013): 57-63.

10. E. Girgis, J. Schelten, J. Shi, J. Janesky, S. Tehrani, and H. Goronkin, Appl. Phys. Lett. 76, 3780 (2000). https://doi.org/10.1063/1.126779.

11. R Kannan, S Ganesan, TM Selvakumari "Structural and magnetic properties of electrodeposited Ni-Fe-WS thin films." Optoelectron Adv Mat, 6, no. 3-4, (2012): 383 388.

12. Venkateshwaran S., Selvakumar E., Senthamil selvan P., Selvambikai M., Kannan R., Pradeep A.S. (2019) Corrosion and Magnetic Characterization of Electroplated NiFe and NiFeW Soft Magnetic Thin Films for MEMS Applications. In: Lakshminarayanan A., Idapalapati S., Vasudevan M. (eds) Advances in Materials and Metallurgy. Lecture Notes in Mechanical Engineering. Springer, Singapore.

13. R Kannan et al, Mater. Res. Express. 5, 046414 (2018). 